\title{
Resilience of US metropolitan areas to the 2008 financial crisis
}

\author{
Nicholas Kreston and Dariusz Wójcik
}

\section{Introduction}

The collapse of property markets beginning in 2006 and banking panic of 2008 marked a major transition for the US economy. The economic expansion of the preceding years masked growing financial instability as investors pursued higher returns from riskier markets, especially the housing sector. With the rapid implosion of expectations for future home price appreciation, credit channel seizure, and the wealth destruction from market failures, residential and business fixed investment plummeted. Compounding this dire situation, the US government at all levels embarked on a policy of fiscal austerity beginning in 2010. This withdrawal, once the funds from the 2009 stimulus package were fully disbursed, left expansionary monetary policy as the sole remaining state effort at recovery. American households, businesses, and public institutions had not been confronted with such a devastating combination of macroeconomic conditions since the Great Depression of the 1930 .

Following the crisis has been a period of stagnation, with the return to a higher growth environment partly contingent on renewed corporate investment and the successful resolution of household financial distress. At the zip code- and countylevels, the distribution of household distress from the inability to service mortgage and consumer debt obligations predicts to a large extent the collapse in income and activity following the crisis (Immergluck, 2009; Mian and Sufi, 2009). However, there has been little research to date on how metropolitan areas have fared over the recession and the association between economic change and the level of financial distress at that scale. The purpose of this chapter is to address that gap.

The metropolitan scale offers a meso-level venue for investigating the distributional consequences of the financial crisis. Framing the problem of uneven growth in resilience terms, we speculate that certain meso-level economic and financial characteristics structure the risk of financial crises and recessions differently among metropolitan areas, but also endow those areas with varying capacity to adjust to changing macroeconomic conditions. Our objectives here are to identify distinct trajectories of crisis and recovery and to determine the extent to which we can associate these divergent trajectories with the economic and financial profile of a metropolitan area, using bank closures and housing market distress as special examples. 
Researching the relationship between financial institutions and economic development at meso-scale, with focus on regional and urban level, is crucial for understanding regeneration economies. On the one hand, financial and business services have been one of the most dynamic sectors of the world economy for decades, key to transition from Fordism to today's flexible and financialized economy. On the other, the financial sector and institutions have been major contributors to economic instability and uneven development, as some regions and cities managed to reinvent themselves as centers of financial and business services, but most have not, leading to the emergence of an 'archipelago economy', in which New York may have increasingly more in common and to do with London and Hong Kong and less with Detroit or Cleveland. Despite much work in financial geography, this complex relationship between finance and development, particularly at regional and urban levels, has been under-researched, due mainly to the lack of systematic financial data at these scales of analysis.

Our objectives are operationalized in the following research questions. First, which areas performed best and worst during the crisis? We approach this question using cluster analysis, dividing the sample of US metropolitan statistical areas (MSAs) into groups based on their ratios of employment and gross domestic (metropolitan) product (GMP) in 2011 to 2007 . Second, to what extent can we attribute divergent growth outcomes to the indicators of metropolitan financial integrity, principally the status of subprime households' balance sheets? Generally, this question aims to evaluate how the failure of financing channels, the destruction of household wealth, collapse in consumer spending, and the lower willingness, ability, or availability to incur new debt may have acted as a source of distress in the recession or as a barrier to recovery in the post-crisis period.

The cluster analysis divides the sample into five groups, on the basis of their performance over the recession-here measured as the ability of an MSA to recover lost activity. The best-performing group was characterized by lower than average levels of economic diversity and low rates of subprime and modified mortgages among households. The worst-performing cluster was also characterized by low average levels of economic diversity but had the highest average rates of bank failures in addition to higher rates of subprime mortgages and mortgages modified under a federal program. Regarding the extent to which these divergent characteristics can be attributed to the subprime markets, however, we find that most variation in the change in growth remains unaccounted for in regression models. Cluster methods are best suited for generating hypotheses, and our findings suggest continued attention to two topics: deeper analysis of the variation in household vulnerability between urban areas; and, a more thorough profiling of metropolitan areas on the basis of their sector specializations in order to determine which sectors or combinations of sectors managed to retain and expand their skilled workforce (which ostensibly reflects the ability to generate or attract new or hold down existing corporate investment).

In the following section, we review the concept of resilience and outline the structural characteristics of metropolitan areas that will be used to analyze the clusters 
created based on economic growth trajectories. Then we describe our data and methodology for the cluster analysis. Our analysis first establishes a benchmark for economic performance among MSAs over the recession and post-crisis periods, then presents the results from the cluster analysis, and finally considers the economic and financial characteristics of MSAs. In the conclusion we offer recommendations for future research.

\section{Growth, recession, and resilience in metropolitan areas}

The concept of resilience has developed a following in economic-geography, bringing polarizing tendencies with it. Proponents argue that irrespective of its conceptual fuzziness, "resilience [reaction and adjustment of regions to shocks] is part of the process of geographically uneven economic evolution and development, and should be theorized and analysed as such" (Martin and Sunley, 2014: 37), while many of its critics object to its normative implications (Bristow, 2010; MacKinnon and Derickson, 2013). Invoking resilience as a theme or conceptual frame as it has come to be deployed in economic-geography involves implicit assumptions not only about what elements of a region are at risk and react to disturbances (and therefore what phenomena merit investigation), but also about whether a region even contains the ability-in terms of its internal resources, its material base and institutions - to extricate itself from certain types of adverse events.

Martin (2012) outlines two main definitions of resilience that involve distinct methodological applications: engineering-based and ecological-, adaptive- or evolutionary-based definitions. The central assumption of the first is that the core economic resources of an area observe a long-run equilibrium, hence disturbances to the growth process will eventually be corrected as part of an innate order of the system. In this case, possible avenues for determining resilience involve measuring the pace of return to trend and the magnitude of divergence or convergence between regions (Fingleton et al., 2012). However, econometric experiments have identified instances where economic shocks, including financial crises (Cerra and Saxena, 2008; Reinhart and Rogoff, 2009), at the level of the nation-state have been incorporated into longterm growth processes in the form of downward revisions to trend, and evidence of permanent, hysteretic effects (Doran and Fingleton, 2014; Fingleton and Palombi, 2013). The possibility of a permanent change in long-run growth trajectories lends credence to the second definition of a resilience, where multiple equilibria exist. Turok (2014, 751-752) has summarized the difference between the two definitions as such: the first is concerned with outcomes (what phenomena was resilient to what disturbance), while the second is concerned with processes (how do areas adapt their structures to constantly fluctuating economic conditions?).

In light of these debates we use the following conventions. First, we evaluate resilience of an MSA as a ratio of economic activity in 2011 to 2007. On the face of it, this metric bears most resemblance to engineering-based definitions, whose origins are typically traced to Holling (1973) and which Martin (2012) argues has a corollary 
in Friedman's (1993) 'plucking model' of the business cycle. Asking whether or not MSAs have returned to their pre-crisis levels of employment and output does not necessarily imply, however, that we accept the dogmatic view that crises and recessions are transient deviations from trend that do not produce durable shifts in long-run growth potential of various regions. Indeed, standard schematics of a financial asset boom involve discrete phase transitions as households or businesses enter into new debt and cash flows arrangements with creditors (Minsky, 1982).

Second, following the discussion of Pendall et al. (2010), who argue that an assumption of long-run equilibrium may be valid in the case of employment and output, we identify metropolitan employment and GDP as the objects of disturbance, and the financial crisis and recession as the form taken by the disturbance. Finally, the MSA is an appropriate territory for comparing resilience. Unlike the neighborhood, zip-code, or county (Aalbers, 2009a; Immergluck, 2009; Mian and Sufi, 2009), the MSA -as an agglomeration of many counties based on the central city pattern-is a natural venue for discussing the role of urban diseconomies, market potential, economic diversity, and the role of regional specializations (embodied, for example, in industrial districts or global cities). The MSA is also appropriate for evaluating regional financial integrity. Walks (2013) proposes the idea of an 'urban debtscape,' or the social and spatial outcomes of indebtedness and relations of credit that capture macro-economic processes like financialization at the city-level. Just as these financial relations of indebtedness can generate divergent outcomes within a city (Aalbers, 2006; Dymski and Veitch, 1996; Wyly et al., 2009), these uneven relations are also evident between cities (Aalbers, 2009b; Wainwright, 2012), ultimately reflecting the imperatives of global capital markets (Sassen, 2009; Wójcik, 2013). Part of the power of resilience as a concept rests in comparison, and our analysis is implicitly framed as an exploration of resilience in terms of the structural relations within and between metropolitan areas.

Three variables describe a metropolitan financial profile: high-cost mortgage loans, bank failures, and mortgages modified under a federal program. This selection addresses three shortcomings in the literature. First, in contrast to the savings and loans (S\&L) crisis (Warf and Cox, 1995, 1996) and the United Kingdom during the 2008 crisis (Marshall et al., 2012; Marshall, 2013), there has been little analysis of the spatial patterns of the 2008 bank panic and subsequent government response in the United States. Second, explanations of local and metropolitan decline for this period tend to invoke the housing bubble and the regional factors behind home price appreciation, such as amenities (Martin, 2010; Carruthers and Mulligan, 2012; Delmelle and Thill, 2014; Rickman and Guettabi, 2015). Such studies are useful as time-series housing prices are widely available for most metropolitan areas and serve as a justifiable proxy for wealth, however prices do not represent any kind of underlying, ongoing social relation, as do debts, for instance. Where asset prices may become unhinged due to 'irrational exuberance' or systematic mispricing, the credit environment speaks of material obligations in a wider socio-financial context.

Finally, there has generally been little comparative work on economic performance over the 2007-2009 recession using US metropolitan areas, a notable exception 
being Gabe and Florida (2013), who also used cluster analysis. Their research raises an interesting point about the nature of the housing bubble collapse and recovery. Although new housing development in the years leading up to 2006 demonstrated a significant and negative impact on employment, activity in the construction sector on its own is not responsible for the distribution of the recession. Rather, the regional pattern of the recession can be explained by a specific combination of construction, retail, and hospitality employment-chief components of what Florida (2010) has called the 'great growth illusion'-that reproduces a specific vision of American homeownership. Those findings are an important reminder to consider the role of particular economic or industrial arrangements in structuring recessionary losses over space.

\section{Methodology and data}

We use hierarchical cluster analysis to identify types of growth trajectories among the sample of MSAs (Everitt et al., 2011). Using Ward's method to divide the sample allows us to avoid deciding a priori the number of clusters. This method starts with all observations in their own cluster, and then at each step merges two clusters to form a larger one. Ward's method uses analysis of variance to determine the distance between clusters, minimizing at each step the sum of squares of a given pair of clusters, therefore maximizing internal homogeneity. The Caliński-Harabasz pseudo-F index is the clustering stop rule, which determines an optimal number of clusters (Caliński and Harabasz, 1974). Related studies that cluster regional data also invoke hierarchical techniques with the Ward method (Gabe and Florida, 2013; Kronthaler, 2005).

Our clustering process is based on two variables: the ratios of total employment and of GMP in 2011 to 2007 for each MSA. The pseudo-F-statistic was greatest in the three- and five-cluster solutions. We selected the five-cluster solution for the reason that a larger number offers greater diversity in the possible trajectories.

The regional economic accounts data of the Bureau of Economic Analysis (BEA) provide annual GMP data at the MSA-level (in millions of current dollars), and is available online. ${ }^{1}$ Employment data were drawn from the US Census online depository $^{2}$ of the County Business Patterns for the years 2007, 2009, and 2011. Using this data, we created variables for FIRE specialization and economic diversity. For the former, we used a location quotient:

$$
L Q_{i j}=\frac{\left(\frac{e_{i j}}{e_{j}}\right)}{\left(\frac{E_{i}}{E}\right)}
$$

1 http://www.bea.gov/regional/.

2 https://www.census.gov/data/datasets/2009/econ/cbp/2009-cbp.html. 
where: $e$ is local employment, $E$ national employment, and $i$ aggregates NAICS codes 52 (finance and insurance) and 53 (real estate) for each location $j$.

A regional distinctiveness index (RDI) described in Markusen and Schrock (2006) captures diversity-the degree to which a metropolitan economic profile deviates from the national average. Using the two-digit NAICS employment data for 19 sectors (excluding public administration and 'other' due to suppressed data), the equation can be specified as:

$$
R D I_{j}=\sum_{i} *\left(\frac{\left|\frac{e i j}{e j}-\frac{E i}{E}\right| * 100}{2}\right)
$$

The equation uses the same notations as equation (1.1).

The range falls between o and 10o, higher scores indicating greater deviation from the cohort. The RDI expresses the relative imbalance of economic activity in favor of specialization in fewer industries, but cannot be used to determine to which sectors the imbalance may be attributed. As with any specialization metric, the trade-off is between its comparative power and reductionism, and at the two-digit level of industrial aggregation this index paints specialization in broad strokes.

There are three final variables that indicate different aspects of the financial integrity of an MSA: bank failure rate, subprime mortgage rate, and mortgage modification rate. To determine the failure rate, we took the number of bank failures in an MSA resolved by the FDIC between 2008 and 2010 as a share of the number of banks headquartered in that MSA as of the end of $2007 .^{3,4}$ The subprime mortgage rate represents the number of high-cost home purchase loans issued between 2004 and 2006 as a percentage of all households in 2010. High-cost refers to an interest rate where the spread between the annual rate of the loan and corresponding Treasury yield exceeds three percentage points. The data for this variable were collected by the Federal Financial Institutions Examination Council (FFIEC). ${ }^{5,6}$ Finally, the mortgage modification rate is the number of modifications (reductions in principal) completed under the auspices of the US Treasury's Home Affordable Modification Plan (HAMP). These data were retrieved from the Treasury website on financial stability. ${ }^{7,8}$ The base population of households that was used to convert both the subprime mortgage and mortgage modification variables into ratios was taken from the FFIEC dataset.

\footnotetext{
3 https://www.fdic.gov/bank/individual/failed/banklist.html.

4 https://www.fdic.gov/bank/statistical/.

5 The Urban Institute provides an in-depth discussion of the dataset, its collection, and methodology online at: http:// www.urban.org/UploadedPDF/1001247_hdma.pdf.

6 https://ci.billings.mt.us/DocumentCenter/View/8135/Map-from-Foreclosure-Risk.

7 http://www.treasury.gov/initiatives/financial-stability/reports/Pages/HAMP-Report.aspx.

8 https:/www.treasury.gov/initiatives/financial-stability/reports/Documents/November\%202012\%20MHA\%20 Report\%2oFinal.pdf.
} 


\section{Robustness and resilience of US metropolitan areas to the 2008 crisis}

A first step in determining metropolitan resilience is to establish benchmarks for economic performance. Using the average of the MSA sample excludes the quarter of US economic activity contained within non-metropolitan and micropolitan areas, so we first present the national totals. Figure 6.1 displays the path of total private employment and GDP in the US, indexed to 2007. According to the National Bureau of Economic Research (NBER), the official beginning of the recent recession was the final quarter of 2007 , ending in the middle of 2009. We adopt this timing, delineating 2007-2009 as the crisis/recessionary period and 2009-2011 as the nominal recovery period. Over the crisis period, US employment declined by 5.05 percent and GDP by 0.43 percent. Over the recovery period, employment declined by 0.95 percent while GDP increased by 7.74 percent. Figure 6.1 shows that GDP appears to be resilient in the technical sense of having 'bounced-back' to trend by 2011 (Martin, 2012), while employment did not surpass its peak between 2007 and 2008 until the beginning of 2014.

Table 6.1 contains descriptive statistics for our independent and dependent variables. One of the most important points is that roughly four years after the beginning or two years after the end of the recession, metropolitan economies remained 94 percent of their pre-recession size, which suggests a jobless recovery.

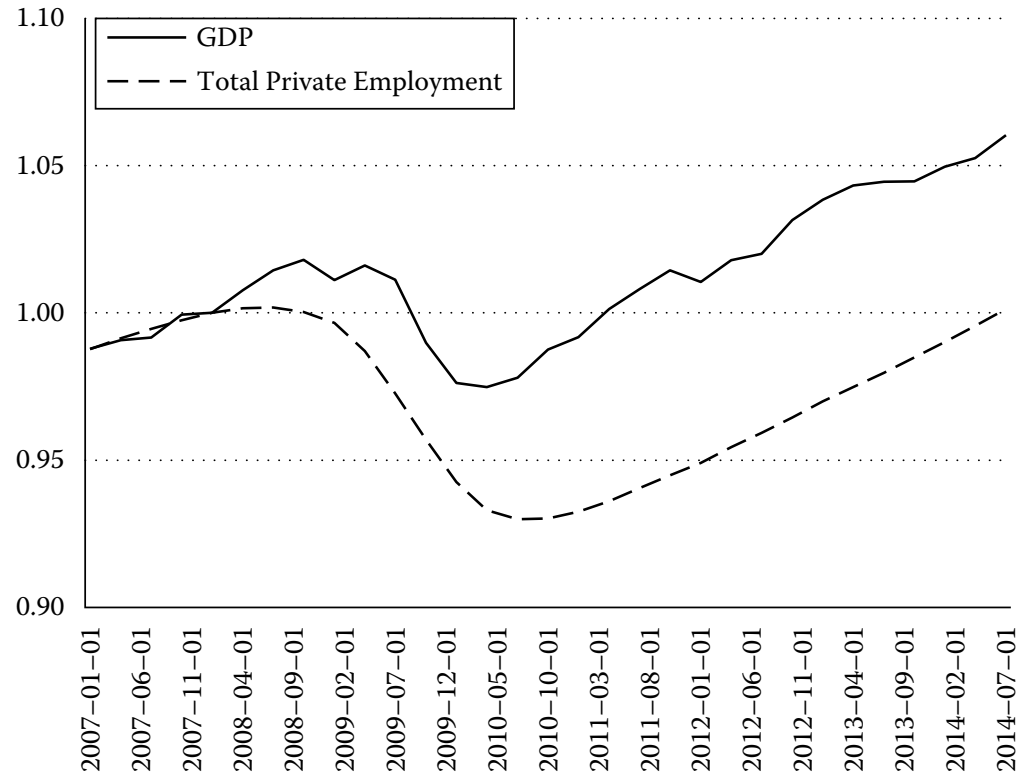

Source: Authors' calculation based on data from US Bureau of Economic Analysis and US Census Bureau.

Figure 6.1 Resilience of employment and GDP in the USA 
Table 6.1 Descriptive statistics

\begin{tabular}{lccccc}
\hline Variable & Obs & Mean & Std. Dev. & Min & Max \\
\hline Employment ratio & 351 & $93.9 \%$ & 0.05 & $78.2 \%$ & $113.3 \%$ \\
GMP ratio & 351 & $108.4 \%$ & 0.08 & $83.4 \%$ & $148.6 \%$ \\
Chg in employment 07-09 & 351 & $-4.7 \%$ & 0.046 & $-25.3 \%$ & $24.1 \%$ \\
Chg in employment 09-11 & 351 & $-1.5 \%$ & 0.028 & $-19.5 \%$ & $10.2 \%$ \\
Chg in GMP 07-09 & 351 & $0.3 \%$ & 0.063 & $-39.1 \%$ & $25.4 \%$ \\
Chg in GMP 09-11 & 351 & $8.1 \%$ & 0.066 & $-2.9 \%$ & $52.7 \%$ \\
FIRE & 351 & 0.598 & 0.314 & 0.00 & 3.76 \\
RDI & 351 & 14.302 & 5.06 & 4.00 & 40.28 \\
Bank failure rate & 351 & $4.7 \%$ & 0.142 & $0.0 \%$ & $100.0 \%$ \\
Subprime mortgage rate & 351 & $2.2 \%$ & 0.009 & $0.4 \%$ & $6.1 \%$ \\
HAMP modifications & 351 & $0.5 \%$ & 0.005 & $0.0 \%$ & $3.1 \%$ \\
Employment (2007) & 351 & 287,197 & 664,710 & 10,825 & $7,671,171$ \\
GMP (2007) (S000s) & 351 & 34,861 & 95,026 & 1,858 & $1,206,207$ \\
\hline
\end{tabular}

Source: Authors' calculation based on data from US Bureau of Economic Analysis, US Census Bureau, FDIC, the Urban Institute, US Treasury (see Methodology).

An equally important point is the financial element of the 2008 crisis and recession, as reported in the bank failure, subprime mortgage, and mortgage modification rates. Approximately five percent of banks chartered in metropolitan areas failed between 2008 and 2010, however the variation among MSAs is large, with some areas seeing all their bank headquarters fail (Carson City, NV; Flagstaff, AZ; Greenville, NC; Merced, CA; and Wilmington, NC). In contrast, subprime (high-cost purchase loans) mortgages affected on average 2 percent of metropolitan households, with much lower variation and a maximum of only 6 percent (in Riverside-San Bernardino, CA). The number of mortgages modified under HAMP also affected a relatively small portion of households, with a maximum of three percent (again in Riverside-San Bernardino; in fact, eight of the top ten MSAs with the highest ratio of mortgage modifications are located in California, joined by Miami-Fort Lauderdale, FL, and Las Vegas-Paradise, NV).

\section{Distress and growth through and after the financial crisis}

The results of the cluster analysis are displayed in Figure 6.2. The worst performing cluster is the second group, and the best is group five. The main distinction between clusters four and five is that group five has the highest GMP ratios, although half of this sample registered an employment ratio less than unity. Table 6.2 records the mean employment and GMP ratios for these clusters in addition to the nine Census divisions of the states. The ratios by Census divisions emphasize the regional dimension of the recession: areas in the West South Central states 


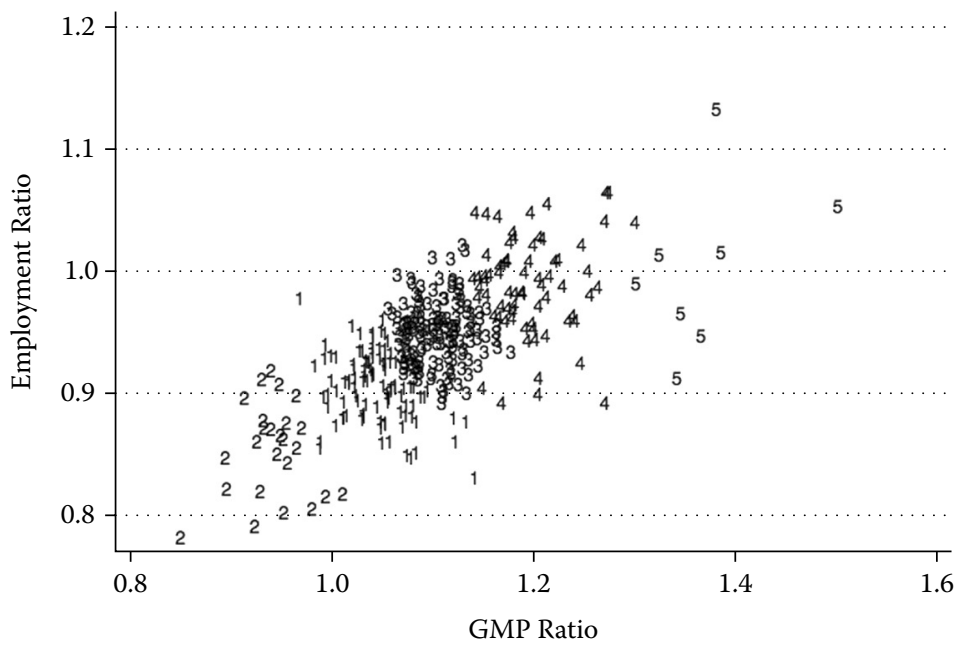

Source: Authors' calculation based on US Bureau of Economic Analysis, US Census Bureau, FDIC, the Urban Institute, US Treasury (see Methodology).

Figure 6.2 Cluster groups by employment and GMP ratios

(Texas, Arkansas, and Louisiana) had the highest averages for employment and GMP, demonstrating the greatest average robustness and/or resilience, whereas those in the East North Central states (Michigan, Wisconsin, Illinois, and Ohio) demonstrated the lowest.

The best- and worst-performing MSAs are unevenly apportioned by Census division. MSAs in cluster 5 are located in either West North Central, South Atlantic, West South Central, or Pacific states. MSAs in cluster 2 are located in either Middle Atlantic, East North Central, South Atlantic, Mountain, or Pacific states. Despite this unevenness, the regional distribution of MSAs does not fully explain the pattern of the economic contraction following the financial crisis and recession.

Table 6.3 contains the mean statistics for the other descriptive variables for the MSA clusters, allowing some generalizations about the capacity of various types of metropolitan areas to weather the 2008 crisis. MSAs in the second cluster-with the lowest average performance in employment and GMP terms-tended to have low FIRE concentrations but high levels of economic specialization, as well as the highest average rates of bank failures and household distress. These areas were also quite small, with an average 112,786 employed in 2007. The largest MSA in this group was Las Vegas, followed by Reno, NV.

The eight MSAs in cluster 5, which experienced the greatest expansion in GMP of the full sample of MSAs over the crisis and recession, are among the smallest in the 
Table 6.2 Employment and GMP ratios

\begin{tabular}{|c|c|c|c|c|}
\hline & & \multirow[t]{2}{*}{ Obs } & \multicolumn{2}{|c|}{ Mean } \\
\hline & & & Emp. ratio & GMP ratio \\
\hline USA & & & 0.94 & 1.07 \\
\hline MSAs & & 351 & 0.94 & 1.08 \\
\hline \multicolumn{5}{|l|}{ MSA Cluster } \\
\hline & 1 & 101 & 0.91 & 1.03 \\
\hline & 2 & 25 & 0.85 & 0.93 \\
\hline & 3 & 146 & 0.95 & 1.09 \\
\hline & 4 & 71 & 0.99 & 1.18 \\
\hline & 5 & 8 & 1 & 1.35 \\
\hline \multicolumn{5}{|l|}{ Census Division } \\
\hline New England & & 15 & 0.95 & 1.06 \\
\hline Middle Atlantic & & 30 & 0.96 & 1.09 \\
\hline E N Central & & 60 & 0.92 & 1.05 \\
\hline W N Central & & 26 & 0.97 & 1.12 \\
\hline S Atlantic & & 71 & 0.93 & 1.07 \\
\hline E S Central & & 28 & 0.93 & 1.09 \\
\hline W S Central & & 42 & 0.99 & 1.16 \\
\hline Mountain & & 34 & 0.92 & 1.06 \\
\hline Pacific & & 45 & 0.92 & 1.07 \\
\hline
\end{tabular}

Source: Authors' calculation based on data from US Bureau of Economic Analysis and US Census Bureau.

sample. These areas were: Bellingham, WA; Fargo, ND; Hinesville, GA; Lafayette, LA; Beaumont, TX (the largest MSA in this group, with employment of 134,765 in 2007); Midland, TX; Elizabethtown, KY; and Jacksonville, NC. These MSAs tended also to have low FIRE concentrations, but a level of sector diversity that was only slightly lower than for the full sample. The bank failure rate of this group was the second highest for all the clusters, however this group had the lowest subprime mortgage and mortgage modification rates.

The characteristics of MSA performance we wish to highlight are growth trajectories and the sources of financial and economic distress. Growth trajectories can be explained first as to whether an MSA was robust and then whether it was resilient; each may have separate causes. The most notable feature of Table 6.2 is that all cluster groups had improved averages in the second period for both change in employment and change in GMP, yet for cluster 2 the change was negligible $(-11.63$ percent in the first period and -11.22 percent in the second). While all other cluster groups could be characterized as somewhat resilient in this respect, this characterization is not applicable in the case of the worst-performing MSAs. As such, in addition to having to explain why MSAs display varying levels of robustness to the 


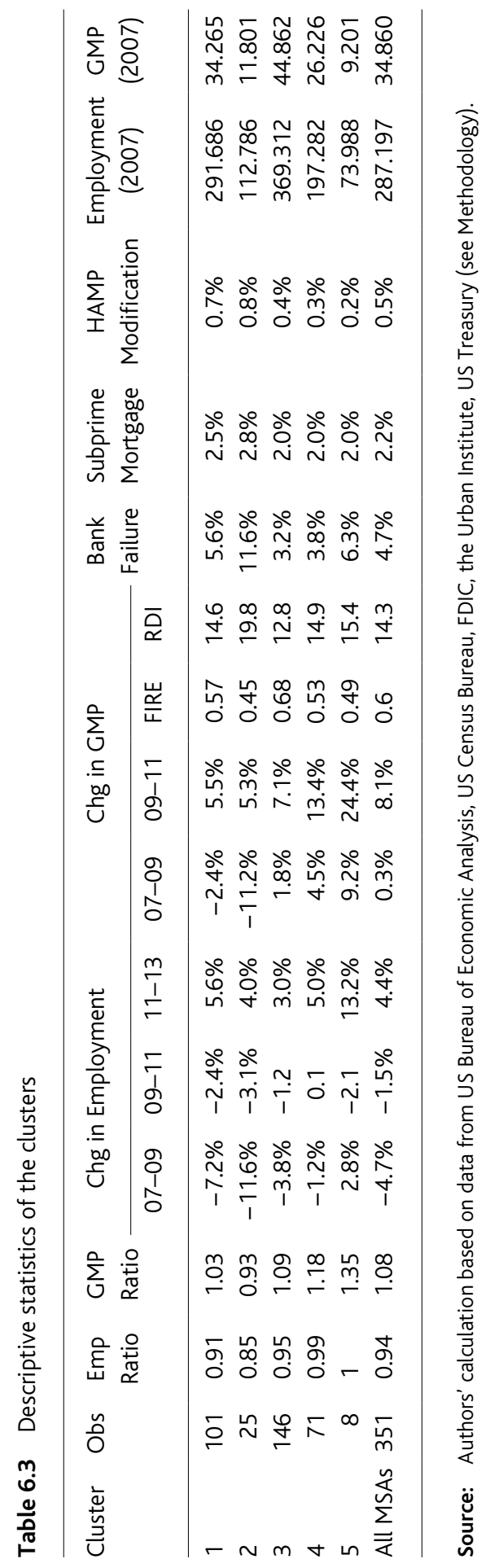


crisis, we must also account for the factors that are stalling recovery for the worst affected MSAs.

One way to explore this problem of delayed recovery with our data is basic OLS regression. The independent variables discussed above were logarithmicallytransformed in order to standardize the coefficients. Table 6.4 presents the OLS estimates. The most revealing observation from all regressions is that the $r$-squared statistic is low for both the recessionary and post-recessionary periods. The majority of variation among MSA economic performance remains unexplained, and in the case of regressions (1) and (2) it is notable that the $r$-squared declined by over half between the two periods. Regarding the statistical significance of each variable, in the regressions with change in employment as the dependent variable, the FIRE and total employment variables were always significant, while the subprime and RDI variables lost their significance in the test of the post-recession sample. The coefficient for the subprime mortgage variable remained negative, however the coefficient itself decreased and lost significance. Again, given its significance and the low $r$-squared, the explanatory power of the severity of the subprime mortgage crisis is limited to the recession years.

Counterintuitively, both size and FIRE reversed their signs between the periods, with size exerting a positive effect and FIRE concentration exerting a negative effect on the growth rate of employment. Evidence for structural impediments of central/ large urban areas in times of economic crises and structural benefits during periods of economic growth/recovery has recently become available. Dijkstra et al. (2015) argue that in the face of adverse shocks, agglomerations may magnify negative effects of crises. Contrarily, Capello et al. (2015) have argued that GDP growth in the largest urban centers (in Europe) was more resilient to the 2008 crisis than growth in smaller urban areas. They point to agglomeration economies, dense external linkages, higher quality infrastructure, and thicker cooperation networks as the source of this resilience. The reversal of the FIRE effect may be explained by the delayed reaction to the crisis by financial companies, who did not begin restructuring and workforce reductions until after 2009 (Wójcik, 2012; Wójcik and MacDonald-Korth, 2015). In regressions (4) and (5), the dependent variable is change in GMP for the appropriate time period. The sign and strength of the coefficients are largely the same, with some exceptions. The coefficients for the recessionary period for economic diversity and total size are larger, while FIRE specialization is not statistically significant; the $r$-squared is commensurate with the regression for change in employment. For the post-recession period, only FIRE specialization is statistically significant (at the 10 percent level), and, again, the $r$-squared has collapsed, although by much less.

The regression results give limited insight into the issue of diverging growth trajectories and sources of distress. Less robust MSAs owe part of the downward pressure in their economic growth during the crisis to the concentration of subprime mortgages and low sectoral diversification. In terms of post-crisis growth, factors that may be responsible for stalled growth include subprime mortgage concentrations in addition to greater FIRE specialization, yet their contribution is marginal. 
Table 6.4 OLS regressions for change in total employment and GMP

(2)

(3)

(4)

(5)

(6)

chg in emp chg in emp chg in emp chg in gmp chg in gmp chg in gmp

\begin{tabular}{|c|c|c|c|c|c|c|}
\hline Log(Subprime & $-0.236^{* * *}$ & -0.072 & -0.08 & $-0.261^{* * *}$ & -0.031 & 0.079 \\
\hline Mortgages) & $(-4.47)$ & $(-1.23)$ & $(-1.09)$ & $(-4.84)$ & $(-0.55)$ & -1.14 \\
\hline Log(Bank Fail & -0.029 & -0.041 & -0.04 & -0.08 & 0.073 & 0.068 \\
\hline Rate) & $(-0.50)$ & $(.0 .64)$ & $(-0.63)$ & $(-1.37)$ & -1.18 & -1.11 \\
\hline \multirow[t]{2}{*}{$\log (\mathrm{RDI})$} & $-0.159 *$ & 0.078 & 0.077 & $-0.246 * * *$ & 0.035 & 0.049 \\
\hline & $(-2.45)$ & -1.08 & -1.06 & $(-3.72)$ & -0.51 & -0.71 \\
\hline \multirow[t]{2}{*}{$\log (\mathrm{FIRE})$} & $0.127^{*}$ & $-0.113+$ & $-0.112+$ & 0.083 & $-0.112+$ & $-0.120^{*}$ \\
\hline & -2.24 & $(-1.79)$ & $(-1.77)$ & -1.42 & $(-1.83)$ & $(-1.99)$ \\
\hline \multirow[t]{2}{*}{ Log(Employment) } & $-0.180^{*}$ & $0.173^{*}$ & $0.168^{*}$ & $-0.269 * * *$ & 0.116 & $0.181^{*}$ \\
\hline & $(-2.48)$ & -2.14 & -1.99 & $(-3.63)$ & -1.49 & -2.23 \\
\hline \multirow[t]{2}{*}{ Log(HAMP) } & & & 0.017 & & & $-0.237^{* *}$ \\
\hline & & & -0.18 & & & $(-2.65)$ \\
\hline \multirow{2}{*}{$\begin{array}{c}\text { Mid-Atlantic } \\
\text { indicator }\end{array}$} & -0.034 & $0.159+$ & $0.162+$ & 0.047 & 0.045 & 0.003 \\
\hline & $(-0.44)$ & -1.86 & -1.86 & -0.61 & -0.55 & -0.03 \\
\hline \multirow{2}{*}{$\begin{array}{c}\text { E N Central } \\
\text { indicator }\end{array}$} & $-0.264^{* *}$ & 0.13 & 0.135 & $-0.237^{*}$ & $0.265^{*}$ & $0.192+$ \\
\hline & $(-2.73)$ & -1.21 & -1.22 & $(-2.40)$ & -2.56 & -1.8 \\
\hline \multirow{2}{*}{$\begin{array}{l}\text { W N Central } \\
\text { indicator }\end{array}$} & 0.055 & 0.051 & 0.057 & 0.055 & $0.164^{*}$ & 0.083 \\
\hline & -0.74 & -0.62 & -0.64 & -0.72 & -2.05 & -0.97 \\
\hline \multirow[t]{2}{*}{ S Atlantic indicator } & -0.1 & 0.036 & 0.04 & 0.114 & 0.031 & -0.026 \\
\hline & $(-0.99)$ & -0.32 & -0.34 & -1.11 & -0.28 & $(-0.24)$ \\
\hline \multirow{2}{*}{$\begin{array}{l}\text { E S Central } \\
\text { indicator }\end{array}$} & -0.046 & 0.024 & 0.03 & 0.075 & 0.059 & -0.023 \\
\hline & $(-0.58)$ & -0.27 & -0.32 & -0.94 & -0.7 & $(-0.26)$ \\
\hline \multirow{2}{*}{$\begin{array}{c}\text { W S Central } \\
\text { indicator }\end{array}$} & $0.232 * *$ & $0.216^{*}$ & $0.226^{*}$ & 0.135 & $0.446 * * *$ & $0.302 * *$ \\
\hline & -2.68 & -2.25 & -2.03 & -1.53 & -4.81 & -2.83 \\
\hline \multirow[t]{2}{*}{ Mountain indicator } & -0.047 & -0.117 & -0.115 & -0.009 & 0.067 & 0.044 \\
\hline & $(-0.58)$ & $(-1.29)$ & $(-1.27)$ & $(-0.11)$ & -0.77 & -0.5 \\
\hline \multirow[t]{2}{*}{ Pacific indicator } & $-0.167+$ & 0.012 & 0.012 & -0.037 & 0.147 & $0.159+$ \\
\hline & $(-1.88)$ & -0.13 & -0.12 & $(-0.40)$ & -1.55 & -1.68 \\
\hline Observations & 358 & 358 & 358 & 358 & 358 & 358 \\
\hline$r$-squared & 0.284 & 0.116 & 0.117 & 0.255 & 0.178 & 0.194 \\
\hline
\end{tabular}

Source: Authors' calculation based on data from US Bureau of Economic Analysis, US Census Bureau, FDIC, the Urban Institute, US Treasury (see Methodology).

As a test of the effect of household balance sheets on economic recovery, we included a variable for the number of permanent modifications achieved under the HAMP program (as a share of total households) per metropolitan area as of December 2011 in the third and sixth regressions in Table 6.3 (for change in employment and in GMP during 2009-2011). The distribution of mortgage principal reductions might explain part of the recovery pattern. Ostensibly, mortgage modification 
would entail relief of financial distress, as households receiving modified terms face lower future payments. It is possible that the relief, by releasing future income from debt amortization, might be directed towards paying down other debts or perhaps even consumer spending. Conversely, those reductions represent losses on the balance sheets of financial institutions. The HAMP variable and the subprime mortgage variable share a correlation coefficient of 0.53 , which suggests that most areas with a severe subprime problem were also the primary beneficiaries of the HAMP action, although almost half the variance remains unexplained. For change in GMP, the coefficient for HAMP reported in Table 6.3 is statistically significant, comparatively large, and raises the $r$-squared statistics. It is also negative, and changes the sign of the subprime mortgage variable to positive (but still statistically insignificant).

It seems that growth remained depressed in MSAs with many HAMP modifications. This may reflect the problem of high re-default rates of modified mortgages under HAMP (SIGTARP, 2013). In other words, the program was ineffective in stemming foreclosures in areas affected by the subprime crisis. The HAMP variable may be a more appropriate indicator of continued household distress that applies to the post-crisis period. While the subprime crisis certainly created a number of barriers and constraints in the metropolitan recovery process by destroying wealth and suppressing consumption, a majority of distress stalling post-crisis employment growth originated outside the balance sheets of the most vulnerable households.

\section{Uneven distribution of employment growth}

It may be the case that our choice of two-year intervals to categorize crisis and recovery years are not long enough to effectively convey the changes in metropolitan economies provoked by the crisis. Adding employment figures for 2013 (see Table 6.3) shows that the recessionary trends for employment growth continued into the 2011-2013 period. Total US metropolitan employment in 2013 remained below 2007 levels by 1.2 million (equal to 1.2 percent of 2007 levels). In the sample of 351 metropolitan areas, only 106 showed employment in 2013 greater than 2007, with an average growth in employment in those areas of 8.2 percent since 2007. In contrast, in the remaining MSAs whose employment bases were in 2013 lower than 2007 , the employment gap was on average 6.2 percent below 2007 levels. This differential growth pattern-a much smaller group of MSAs receiving a significantly higher level of growth while the majority of areas continued to lag behind a full four years after the bottom of the recession-is, in itself, a startling fact about the American economic landscape after the crisis.

Another startling set of facts about the post-crisis American economic landscape is the sectorial distribution of employment gains and losses since the end of the recession. Between 2009 and 2013, the national employment base grew by 1.9 million. The four sectors that contributed most to that growth were health care (1.6 
million), accommodation and food services $(781,000)$, administrative, support, and waste services $(759,000)$, and professional services $(298,000)$. By contrast, the loss in employment in construction was 708,000, 690,000 in manufacturing, 195,000 in information, and 148,00o in finance and insurance. In other words, total employment expanded in sectors with traditionally lower wages, fewer retirement and workplace benefits, and more volatile hiring patterns, while it remained depressed in more innovative sectors with traditionally higher wages and benefits and more opportunities to develop human capital. Nonetheless, many of the MSAs that witnessed growth after 2009 saw employment expand in sectors that at the national level saw contraction.

One group of MSAs that grew strongly after 2009 were diversified economies featuring a greater presence of advanced business services firms, corporate headquarters, and other professional services, including major research universities. MSAs in this group include Boston, MA, Charlotte, NC, Denver, CO, New York, NY, San Jose, CA, Washington, DC. For instance, from 2009 to 2013, Charlotte (headquarters to Bank of America, BB\&T, and TIAA-CREF among others) saw its finance and insurance sector expand by 4.2 percent and its professional services sector expand by 7.8 percent. Denver saw its professional services sector expand by 6.9 percent, while San Jose saw its information sector expand by 28.1 percent, its financial sector by 3.9 percent, and its professional services sector by 8.3 percent. Of this small group, Boston, Charlotte, Denver, New York, and Washington were placed in cluster 3 while San Jose was in cluster 4.

Another group of MSAs exhibiting strong post-crisis growth are areas in Texas, Louisiana, and Great Plains states that benefited from the boom in oil and gas. While the major MSAs of the Gulf region-Austin, TX, Dallas, TX, Houston, TX, San Antonio, TX-are direct beneficiaries of the oil and gas boom, they also have been experiencing a significant volume of capital inflows and corporate relocations for many years. Among growing or relocating firms in recent years are Charles Schwab, VISA, Apple, Samsung, Intel, and Facebook in Austin, manufacturing firms Hyundai and Raytheon in Dallas, and Toyota, Boeing, and Oracle in San Antonio. These four Texan MSAs were in either cluster 3 or 4 .

The main drivers of the post-crisis growth model are revealed in these two groups of MSAs: the oil and gas boom and the advanced business services sector. In other words, the crisis period, as in any other recessionary period, featured yet another round of consolidation and relocation within the corporate economy-a process that has been unfolding in the US for decades (Sassen, 2001). Robust and resilient metropolitan areas were drawn from those hosting the oil and gas industry and from the group of regional and national centers that are keyed into the global financial and advanced business services markets. Despite the contraction in the information, financial services, and manufacturing sectors at the national level, a select group of MSAs witnessed expansion in these sectors and in total employment. 


\section{Directions for future research}

Our focus on bank and housing market indicators may give the false impression that metropolitan recovery is exclusively a matter of restoring household (scaling up to metropolitan) financial health. Critical to the issue of how metropolitan areas have moderated the impact of the recession and recovery is the volume of corporate investment. As the regression models show, we cannot point to housing markets as the singular moderator of metropolitan resilience and robustness. Rather, these traits may belong only to the group of metropolitan areas that were successful before the crisis at playing the game of attracting and holding down corporate investment. Beginning our analysis in 2007 leaves out the successive rounds of manufacturing consolidation across many cities and regions since the 1980 os and 1990s. Post-crisis economic stresses cannot be blamed exclusively on the banking crisis and recession; the crisis intensified already fragile economies, which the subprime mortgage and HAMP indicators point to. In a country whose economic system increasingly rests on a services sector that caters to multinational corporations, financial markets, the creative class, and the affluent, American cities that were not competing for corporate investment before the crisis cannot reasonably be expected to have been capable of 'recovering' after 2008 given they were and remain in a state of stagnation or decline.

Cluster analysis is best suited for generating hypotheses, and we have elaborated on at least two hypotheses that merit continued attention. First, based on the insights from the high-cost mortgage and HAMP variables, we suggest that the financial relations of various demographic groups will have varying effects on growth within and between metropolitan areas. Specifically, the contribution of debts and incomes of some segments may be particularly relevant during periods of contraction and others during periods of recovery. The ability and willingness of households to spend, for businesses to undertake investment, or for the government to invest and make transfers will matter at different times, but within these broad sectors there are also important differences in terms of quality and nature of debt-financed activity, as we have suggested in the case of subprime borrowers. One particularly neglected and promising area of research here is the study of regional, urban, and local consumption patterns, the ways in which this consumption is funded, and how it depends on demographic characteristics and migration flows among other factors.

Second, there is room to explore how different types of territorial configurations, as well as economic diversity more generally, affect their robustness and resilience to financial downturns. We need more spatial econometric studies which explore the relationship between growth, stability and inequality and the economic structure and linkages at regional and urban levels. This should be facilitated by emerging big data on financial transactions assembled by private data providers. To explore the role of agency in these configurations, we need to complement spatial econometrics with individual and comparative case studies, which investigate the bargaining relationships and strategic coupling between companies, including those in 
financial and business services, and regions. Finally, we must remember that any study of regeneration economies, particularly when it involves finance, is ultimately an exercise in political economic geography. The US presidential election and the UK's EU referendum of 2016 demonstrated clearly that regions that did not experience successful regeneration in the decades of deindustrialization since the 1980s, and more recently failed to recover from the banking crisis of 2008 , voted against the political status quo, leading to Brexit, and most likely a more protectionist economic policy in the US, combined with a possible rollback of post-2008 financial regulation. Understanding regeneration economies is thus key to understanding both the economic and political origins of our time as well as our future.

\section{Acknowledgements}

Dariusz Wójcik has received funding for his work on the chapter from the European Research Council (ERC) under the European Union's Horizon 2020 research and innovation program (grant agreement number 681337). The chapter reflects only the authors' views and the ERC is not responsible for any use that may be made of the information it contains.

\section{References}

Aalbers, Manuel B. 2006. "When the Banks Withdraw, Slum Landlords Take Over' : The Structuration of Neighbourhood Decline through Redlining, Drug Dealing, Speculation and Immigrant Exploitation." Urban Studies 43 (7): 1061-1086.

Aalbers, Manuel B. 2009a. "The Sociology and Geography of Mortgage Markets: Reflections on the Financial Crisis." International Journal of Urban and Regional Research 33 (2): 281-290.

Aalbers, Manuel B. 2009b. "Geographies of the Financial Crisis." Area 41 (1): 34-42.

Bristow, Gillian. 2010. "Resilient Regions: Re-'place'ing Regional Competitiveness." Cambridge Journal of Regions, Economy and Society 3: 153-167.

Caliński, T., and J. Harabasz. 1974. "A Dendrite Method for Cluster Analysis." Communications in Statistics 3 (1): 1-27.

Capello, Roberta, Andrea Caragliu, and Ugo Fratesi. 2015. "Spatial Heterogeneity in the Costs of the Economic Crisis in Europe: Are Cities Sources of Regional Resilience?” Journal of Economic Geography 15: 951-972.

Carruthers, John, and Gordon F. Mulligan. 2012. "The Plane of Living and the Precrisis Evolution of Housing Values in the USA." Journal of Economic Geography 12: 739-773.

Cerra, Valerie, and Sweta Chaman Saxena. 2008. "Growth Dynamics: The Myth of Economic Recovery." American Economic Review 98 (1): 439-457.

Delmelle, Elizabeth C., and Jean-Claude Thill. 2014. "Neighborhood Quality-of-Life Dynamics and the Great Recession: The Case of Charlotte, North Carolina." Environment and Planning A 46 (4): 867-884.

Dijkstra, Lewis, Enrique Garcilazo, and Philip McCann. 2015. "The Effects of the Global Financial Crisis on European Regions and Cities." Journal of Economic Geography 15 (5): 935-949.

Doran, Justin, and Bernard Fingleton. 2014. "Economic Shocks and Growth: Spatio-Temporal Perspectives on Europe's Economies in a Time of Crisis." Papers in Regional Science, (93): S137-S165. 
Dymski, Gary A., and John M. Veitch. 1996. "Financial Transformation and the Metropolis: Booms, Busts, and Banking in Los Angeles." Environment and Planning A 28: 1233-1260.

Everitt, Brian, Sabine Landau, Morven Leese, and Daniel Stahl. 2011. Cluster Analysis 5th edn. Chichester: Wiley.

Fingleton, Bernard, Harry Garretsen, and Ron Martin. 2012. "Recessionary Shocks and Regional Employment: Evidence on the Resilience of UK Regions." Journal of Regional Science 52 (1): 109-133.

Fingleton, Bernard, and Silvia Palombi. 2013. "Spatial Panel Data Estimations, Counterfactual Predictions, and Local Economic Resilience among British Towns in the Victorian Era." Regional Science and Urban Economics 43 (4): 649-66o.

Florida, Richard. 2010. The Great Reset. Canada: Random House.

Friedman, Milton. 1993. “The 'Plucking Model' of Business Fluctuations Revisited." Economic Inquiry 31 (2): 171-177.

Gabe, Todd M., and Richard Florida. 2013. "Effects of the Housing Boom and Bust on U.S. Metro Employment." Growth and Change 44 (3): 391-414.

Holling, C.S. 1973. "Resilience and Stability of Ecological Systems." Annual Review of Ecology and Systematics 4 (January): 1-23.

Immergluck, Dan. 2009. "The Foreclosure Crisis, Foreclosed Properties, and Federal Policy: Some Implications for Housing and Community Development Planning." Journal of the American Planning Association 75 (4): 406-423.

Kronthaler, Franz. 2005. "Economic Capability of East German Regions: Results of a Cluster Analysis." Regional Studies 39 (6): 739-750.

MacKinnon, Danny, and Kate Driscoll Derickson. 2013. "From Resilience to Resourcefulness: A Critique of Resilience Policy and Activism." Progress in Human Geography 37 (2): 253-270.

Markusen, Ann, and Greg Schrock. 2006. "The Distinctive City: Divergent Patterns in Growth, Hierarchy, and Specialisation." Urban Studies 43 (8): 1301-1323.

Marshall, J. Neill. 2013. "A Geographical Political Economy of Banking Crises: A Peripheral Region Perspective on Organisational Concentration and Spatial Centralisation in Britain." Cambridge Journal of Regions, Economy and Society, 6 (3): 455-477.

Marshall, J. Neill, Andy Pike, Jane S. Pollard, J. Tomaney, Stuart Dawley, and J. Gray. 2012. "Placing the Run on Northern Rock." Journal of Economic Geography 12: 157-181.

Martin, Ron. 2010. "The Local Geographies of the Financial Crisis: From the Housing Bubble to Economic Recession and Beyond." Journal of Economic Geography 11: 587-618.

Martin, Ron. 2012. "Regional Economic Resilience, Hysteresis and Recessionary Shocks." Journal of Economic Geography 12 (1): 1-32.

Martin, Ron, and Peter Sunley. 2015. "On the Notion of Regional Economic Resilience: Conceptualization and Explanation." Journal of Economic Geography, 15 (1): 1-42.

Mian, Atif, and Amir Sufi. 2009. "The Consequences of Mortgage Credit Expansion: Evidence from the U.S. Mortgage Default Crisis.” The Quarterly Journal of Economics 124 (4): 1449-1496.

Minsky, Hyman P. 1982. Can "It" Happen Again? Armonk, NY: M.E. Sharpe.

Pendall, Rolf, Kathryn A. Foster, and Margaret Cowell. 2010. "Resilience and Regions: Building Understanding of the Metaphor." Cambridge Journal of Regions, Economy and Society 3 (1): 71-84.

Reinhart, Carmen, and Kenneth Rogoff. 2009. "The Aftermath of Financial Crises." American Economic Review 99: 466-472.

Rickman, Dan S., and Mouhcine Guettabi. 2015. "The Great Recession and Nonmetropolitan America." Journal of Regional Science 55(1): 93-112.

Sassen, Saskia. 2001. The Global City: New York, London, Tokyo. Princeton: Princeton University Press.

Sassen, Saskia. 2009. "When Local Housing Becomes an Electronic Instrument: The Global Circulation of Mortgages-A Research Note." International Journal of Urban and Regional Research 33 (2): 411-426.

SIGTARP. 2013. Rising Redefaults of HAMP Mortgage Modifications Hurt Homeowners, Communities, 
and Taxpayers. Quarterly Report to Congress. Washington, DC: Office of the Special Inspector General for the Troubled Asset Relief Program.

Turok, Ivan. 2014. "The Resilience of South African Cities a Decade after Local Democracy." Environment and Planning A 46 (4): 749-769.

Wainwright, Thomas. 2012. "Number Crunching: Financialization and Spatial Strategies of Risk Organization." Journal of Economic Geography 12: 1267-1291.

Walks, Alan. 2013. "Mapping the Urban Debtscape: The Geography of Household Debt in Canadian Cities." Urban Geography 34 (2): 153-187.

Warf, Barney, and Joseph C. Cox. 1995. "US Bank Failures and Regional Economic Structure." The Professional Geographer 47 (1): 3-16.

Warf, Barney, and Joseph C. Cox. 1996. "Spatial Dimensions of the Savings and Loans Crisis." Growth and Change 27: 135-155.

Wójcik, Dariusz 2012. "The End of Investment Bank Capitalism? An Economic Geography of Financial Jobs and Power." Economic Geography 88: 345-368.

Wójcik, Dariusz. 2013. "The Dark Side of NY-LON: Financial Centres and the Global Financial Crisis." Urban Studies 50 (13): 2736-2752.

Wójcik Dariusz, and Duncan MacDonald-Korth. 2015. "The British and the German Financial Sectors in the Wake of the Crisis: Size, Structure, and Spatial Concentration." Journal of Economic Geography 15: 1033-1054.

Wyly, Elvin, Markus Moos, Daniel Hammel, and Emanuel Kabahizi. 2009. "Cartographies of Race and Class: Mapping the Class-Monopoly Rents of American Subprime Mortgage Capital." International Journal of Urban and Regional Research 33 (2): 332-354. 